\title{
COVID-19 Cannot Sustainably Improve Air Quality: Evidence from Reopening an Economy
}

\author{
Xiaoxuan Yang \\ Harris School of Public Policy, University of Chicago, Chicago, United States of America \\ Email address: \\ xyang5@uchicago.edu

\section{To cite this article:} \\ Xiaoxuan Yang. COVID-19 Cannot Sustainably Improve Air Quality: Evidence from Reopening an Economy. Journal of Health and \\ Environmental Research. Vol. 7, No. 2, 2021, pp. 88-98. doi: 10.11648/j.jher.20210702.12
}

Received: March 10, 2021; Accepted: March 26, 2021; Published: April 7, 2021

\begin{abstract}
One "silver lining" of the COVID-19 pandemic has been the reduction in air pollution that followed lockdowns. Unfortunately, this unintended air pollution decline will likely be short-lived. As regions begin to recover their economies, travel and industrial activity will increase the ambient pollutants quickly offsetting the improvement in air quality. Therefore, it is urgent to clarify the causal impact of reopening an economy on air quality during COVID-19. Based on city-level daily air quality data in China, this paper is the first to empirically analyze the causal effect of reopening the economy in the provincial capital Lanzhou on concentrations of four air pollutants using the synthetic control method. The results show that the reopening caused a significant increase in the concentration of $\mathrm{NO}_{2}$ by as much as $30 \mu \mathrm{g} / \mathrm{m}^{3}$ (an increase of $75 \%$ from the lockdown level) and a significant increase in $\mathrm{O}_{3}$ concentrations by $60 \mu \mathrm{g} / \mathrm{m}^{3}$ (a $60 \%$ increase) which peaked on the 6th day after the restart. The reopening also led to significant fluctuations in $\mathrm{SO}_{2}$ and $\mathrm{CO}$ concentrations. This study contains useful conclusions by providing timely and reliable causal evidence on the lasting impact of COVID-19 on air quality.
\end{abstract}

Keywords: COVID-19, Air Quality, Reopening Economies, Synthetic Control Method

\section{Introduction}

COVID-19 first appeared in the city of Wuhan in the Hubei Province of China in early December of $2019[1,2]$ and spread mainly through human-to-human contact [3]. Before the successful development of the novel COVID-19 vaccines from Pfizer and Moderna, many countries have considered and implemented measures to restrict human mobility as part of their response plan [4-7]. Surprisingly, a perceived improvement in air quality became evident from the early days of these lockdowns. With the closure of many shops and businesses, reduced industrial activity and vehicle use, reports of noticeably lower pollution levels emerged. These reports first appeared in China and then in many other countries [8-11]. Such unintended improvements in air quality along with the possible associated health benefits offer a "silver lining" to the overwhelmingly negative impacts of this epidemic [12].

Recent studies have quantified the positive environmental impact of the global lockdown and the slowdown of economic activity. He et al. show that lockdown measures in China reduced the Air Quality Index (AQI) and the fine particulate matter $\left(P M_{2.5}\right)$ concentrations by $22 \%$ and $24 \%$ respectively, within weeks of the lockdown [13]. Almond et al. also focus on air pollution in China during COVID-19. They determined that while nitrogen dioxide $\left(\mathrm{NO}_{2}\right)$ emissions declined precipitously, the improvement in sulfur dioxide $\left(\mathrm{SO}_{2}\right)$ emissions was small [14]. Similarly, Cole et al. found that $\mathrm{NO}_{2}$ and coarse particulate matter $\left(P M_{10}\right)$ concentrations fell by $63 \%$ and $35 \%$ respectively during the Wuhan COVID-19 lockdown, while $\mathrm{SO}_{2}$ and carbon monoxide ( $\mathrm{CO}$ ) concentrations did not decrease significantly [12]. Cicala et al. focused on the impact of reduced vehicle usage and electricity consumption on pollution emissions and expected deaths due to stay-at-home policies in the United States. The authors calculate that reductions in emissions from reduced travel and electricity usage reduced deaths by over 360 people per month. Further, they estimate that carbon dioxide $\left(\mathrm{CO}_{2}\right)$ emissions from these sources declined by 46 million metric tons per month [15]. Brodeur et al. examine the causal effect of safer-at-home policies on air pollution across U.S. counties. They find an approximately $25 \%$ reduction in $P M_{2.5}$ concentrations and a 
reduction of the incidence of county-days with an AQI of code yellow or above by two-thirds [16]. Dang and Trinh confirm the results from most individual country or city studies showing that lockdowns reduce air pollution. They find that after 90 days of lockdown, global reduction in $\mathrm{NO}_{2}$ and $P M_{2.5}$ hovered around $9 \%$ and $4 \%$, respectively [17].

However, this temporary respite in air quality is likely to be short-lived, as it requires a billion people staying indoors and millions falling back into poverty. As regional economies begin to recover from the COVID-19 pandemic, industrial activity and human mobility will again release pollutants into the environment so that air quality improvement will be quickly offset. It can be seen that the long-term impact of COVID-19 on air quality will depend on the response of countries and corporations to the economic crisis. It is urgent to further study this issue because so far there has been little research focusing on the impact of reopening an economy on air quality during COVID-19.

After Chinese authorities officially confirmed human-to-human transmission of the virus on January 20, 2020, China implemented multiple non-pharmaceutical interventions (NPIs) to curb the spread of COVID-19. On the national level, COVID-19 was classified as a statutory class B infectious disease on January 20. Prevention and control measures for class A infectious diseases (including only plague and cholera) were instituted. At the provincial level, Zhejiang, Hunan, and Guangdong were the first to activate the Level I public health emergency response on January 23. With the final activation in Tibet, all 31 provinces and equivalent administrative units on the Chinese mainland (hereafter provinces) had declared a Level I response by January 29 [2]. As the spread of COVID-19 in China was effectively suppressed [18], the first decision to lower the response level from the top level to the third level was made in Gansu province at 2: 00 p.m. on February 21, 2020. Liaoning and Guizhou provinces made the same decision on February 22 and 23 respectively, followed by additional provinces successively lowering their emergency response levels to the COVID-19 threat. The downgrading of the emergency response level indicated that the focus of each province began to shift to the restoration of economic and social order. This provides us with a unique natural experiment allowing us to investigate how air pollution levels responded to the reopening economies during COVID-19.

The goal of our analysis is to quantify the causal impact of reopening the economy on local air pollution levels and to provide important empirical evidence for other countries. This paper is the first to quantify the causal impact of reactivating the economy in Lanzhou, the capital city of Gansu province, on local concentrations of four air pollutants by applying the synthetic control method based on city-level daily air quality data in China. The results show that concentrations of $\mathrm{NO}_{2}, \mathrm{SO}_{2}, \mathrm{O}_{3}$, and $\mathrm{CO}$ in Lanzhou increased significantly following its reopening. Specifically, $\mathrm{NO}_{2}$ concentrations increased significantly by as much as $30 \mu \mathrm{g} / \mathrm{m}^{3}$, while $O_{3}$ concentrations increased significantly by $60 \mu \mathrm{g} / \mathrm{m}^{3}$ but peaked on the 6th day after reopening. It is notable that these increases resulted in a $75 \%$ increase in $\mathrm{NO}_{2}$ concentrations from a level very close to the WHO safe limit $\left(40 \mu \mathrm{g} / \mathrm{m}^{3}\right)$ during the lockdown and a $60 \%$ increase in $\mathrm{O}_{3}$ from the safe limit $\left(100 \mu \mathrm{g} / \mathrm{m}^{3}\right)$. We also find that the reopening caused significant fluctuations in concentrations of $\mathrm{SO}_{2}$ and $\mathrm{CO}$.

This study is novel because we employ the synthetic control method developed by Abadie and Gardeazabal [19] and Abadie et al. [20] that allows for a more objective assessment of the air quality impacts of economic reopening. By reproducing the counterfactual outcome trajectory that the treated group would have experienced in the absence of the intervention using a weighted average of available control units, the synthetic control method overcomes the sample selection bias and policy endogeneity problems that can occur in the selection of control groups in previous empirical approaches. Second, although China has implemented a large number of intensive policy adjustments as the rapid spread of the virus has been contained, this study uniquely disentangles and quantifies the causal impact of reactivation on local air quality by selecting an appropriate sample time window. Third, $\mathrm{SO}_{2}, \mathrm{O}_{3}$, and $\mathrm{CO}$ are all "criteria air pollutants" according to the U.S. Environmental Protection Agency (EPA), but have rarely appeared in previous discussions and studies of the impact of COVID-19 on air quality. This paper examines these three pollutants, in addition to $\mathrm{NO}_{2}$, to determine the effect of reopening an economy on the concentrations of different air pollutants. Finally, as downward pressure on the world economy grows, this paper enriches the environmental economics and epidemiological research on the persistent effects of COVID-19 on air quality, contributes to the evaluation of economic stimulus packages that consider climate change, and provides timely policy guidance to all countries.

The remainder of the paper is organized as follows: Section 2 introduces the identification strategies used in this study. Section 3 describes the data and empirical results. Section 4 performs robustness checks to assess the credibility of synthetic control counterfactuals and measures the significance of the reactivation effect. Section 5 concludes.

\section{Identification Strategy}

The difference in differences (DID) technique and propensity score matching (PSM) were commonly used in the prior literature for causal inference and policy evaluation. Nevertheless, the DID method is arbitrary and subjective for the selection of the reference group. Also, systematic differences between the treated city and the control city may account for the implementation of the policy in the target city, leading to policy endogeneity. Besides, the parallel trend assumption is often difficult to maintain in practice because unobserved confounders may have time-varying effects on the results. While the PSM approach controls the influence of observable variables, hidden biases will occur if the selection is based on unobservable variables. Further, the PSM-DID 
design cannot control for unobservable factors that change over time.

In contrast, the synthetic control method (SCM) $[18,19]$ overcomes these inherent disadvantages of the above techniques. Other advantages of applying a SCM approach include: (1) The transparency of the counterfactual allows the weights to be validated because the contribution of each control unit to the entire synthetic unit is explicitly reflected [21]. (2) No extrapolation is required and the synthetic weights are selected and calculated without using the post-intervention data, ruling out the risk of specification cherry-picking or p-hacking [12]. Athey and Imbens believe that the SCM method is "arguably the most important innovation in the policy evaluation literature in the last 15 years" [22].

The SCM technique allows us to construct a "synthetic" Lanzhou using a weighted average of a set of control cities. The goal of the synthetic Lanzhou is to reproduce the trajectory of real Lanzhou in terms of air pollution levels before reopening. Then, the trajectory difference between the synthetic and real Lanzhou after the reactivation can be summarized as the causal effect of reopening.

Given the effectiveness of policy implementation, we choose each provincial capital instead of the province as the unit of observation for this study. The outcome variables of interest in this study are daily city-level concentrations of four pollutants: $\mathrm{NO}_{2}, \mathrm{SO}_{2}, \mathrm{O}_{3}$, and $\mathrm{CO}$. Following the conventional setting used by Abadie et al. [20], suppose we observe the outcome of $K+1$ cities during the period

$$
\sum_{k=2}^{K+1} w_{k} Y_{k t}=\delta_{t}+\theta_{t} \sum_{k=2}^{K+1} w_{k} Z_{k}+\lambda_{t} \sum_{k=2}^{K+1} w_{k} \mu_{k}+\sum_{k=2}^{K+1} w_{k} \varepsilon_{k t} .
$$

Suppose that there are $\left(w_{2}^{*}, \ldots, w_{K+1}^{*}\right)$ such that

$$
\sum_{k=2}^{K+1} w_{k}^{*} Y_{k 1}=Y_{11}, \sum_{k=2}^{K+1} w_{k}^{*} Y_{k 2}=Y_{12}, \sum_{k=2}^{K+1} w_{k}^{*} Y_{k T_{0}}=Y_{1 T_{0}} \text {, and } \sum_{k=2}^{K+1} w_{k}^{*} Z_{k}=Z_{1} .
$$

If $\sum_{t=1}^{T_{0}} \lambda_{t}^{\prime} \lambda_{t}$ is nonsingular, then,

$$
Y_{1 t}^{N}-\sum_{k=2}^{K+1} w_{k}^{*} Y_{k t}=\sum_{k=2}^{K+1} w_{k}^{*} \sum_{s=1}^{T_{0}} \lambda_{t}\left(\sum_{n=1}^{T_{0}} \lambda_{n}^{\prime} \lambda_{n}\right)^{\prime} \lambda_{s}^{\prime}\left(\varepsilon_{k s}-\varepsilon_{1 s}\right)-\sum_{k=2}^{K+1} w_{k}^{*}\left(\varepsilon_{k t}-\varepsilon_{1 t}\right) .
$$

Abadie et al. have proved that the right-hand side of equation (4) converges to zero under several parsimonious requirements [20]. Therefore, after reopening $\left(t \geq T_{0}\right)$, $\sum_{k=2}^{K+1} w_{k}^{*} Y_{k t}$ can be used as an unbiased estimate of $Y_{1 t}^{N}$ to evaluate the effect of the reactivation.

The weight vector $W^{*}=\left(w_{2}^{*}, \ldots, w_{K+1}^{*}\right)^{\prime}$ is chosen by minimizing the distance function $\left\|X_{1}-X_{0} W\right\|_{V}=$ $\sqrt{\left(X_{1}-X_{0} W\right)^{\prime} V\left(X_{1}-X_{0} W\right)}$. In this function, $X$ denotes the feature vector of cities, which corresponds to the observable control variable $\mathrm{Z}$ and the outcome $Y$ before reopening. The importance of different feature vector $X$ in constructing weights depends on the selection of the symmetric and positive semidefinite matrix $V$. We include in $X$ the values of predictors of air pollution levels for Lanzhou and the remaining 14 potential controls. Our predictors of the concentration of each pollutant are gross regional product per capita (GRPper) and industrial structure (Indushare). These variables are averaged over the January 30-February 2 period and augmented by adding the corresponding pollutant concentrations on specific days.

\section{Empirical Analysis}

\subsection{Data Source and Variable Selection}

The data used in this study were obtained from multiple open-access databases. City-level daily concentrations of four pollutants $\left(\mathrm{NO}_{2}, \mathrm{SO}_{2}, \mathrm{O}_{3}\right.$, and $\left.\mathrm{CO}\right)$ for 31 Chinese provincial capitals were collected from China's online air quality monitoring and analysis platform, which provides hourly updated data on weather information for 367 Chinese cities. Moreover, daily temperature data comes from the Weather Post-Report website. Investment in environmental governance, demographics, and socio-economic development data for each city were taken from the China Environment Yearbook 2019 and the China City Statistical Yearbook 2019.

Our sample data, which covers 31 cities in China 
between January and March 2020, is generated by matching the above datasets by city name and date and retaining only all provincial capitals from the Chinese mainland. With the effective control of the COVID-19 pandemic, Gansu province was the first to lower the public health emergency response from Level I to Level III at 2: 00 p.m. on February 21, 2020. Liaoning and Guizhou provinces then made the same decision on February 22 and 23 respectively. Most of the other provinces in our sample have also successively downgraded their emergency response levels since February 28, making them unsuitable to remain as potential control units. Thus, in order not to attenuate the reactivation effect estimate that we obtain for Lanzhou, we restrict our data period to February 27 and discard other restarted cities other than Lanzhou before then. This means that our analysis is limited to one week after reopening. We set the Lanzhou reopening date as February 21, 2020, to match the official government announcement that the province in which this city is located will reopen on that date. Abadie suggests that if there is an anticipation effect, the researchers should backdate the intervention date in order to fully estimate the entire scope of the policy intervention [21]. We therefore tested different starting dates and are assured that our results are not sensitive to the choice of date.

\subsection{Empirical Results}

Figure 1 plots the daily trends in $\mathrm{NO}_{2}, \mathrm{SO}_{2}, \mathrm{O}_{3}$, and $\mathrm{CO}$ concentration levels in Lanzhou (red line) and other Chinese provincial capitals (dashed grey line). As this figure suggests, the time series of Lanzhou before reopening the economy is notably different from that of other cities in China. Concentrations of the four air pollutants have remained stable in other cities since the activation of the Level I public health emergency response, while the concentration of each air pollutant in Lanzhou is generally higher than that in other cities in China and is accompanied by more dramatic fluctuations. Therefore, other cities in China may not provide a suitable comparison group for Lanzhou to study the impact of reopening the economy on local air pollution levels.
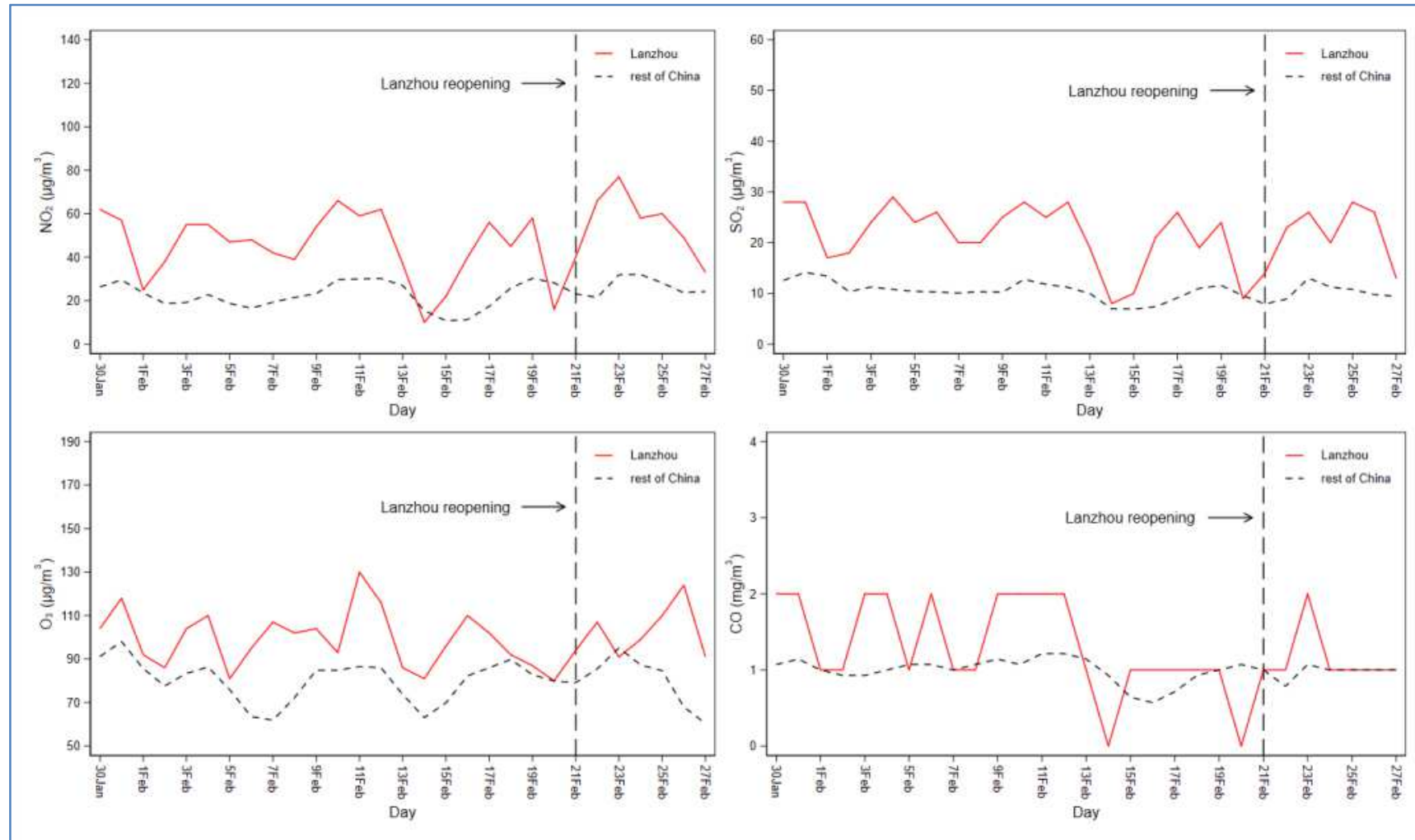

Figure 1. Trends in concentrations of $\mathrm{NO}_{2}, \mathrm{SO}_{2}, \mathrm{O}_{3}$, and $\mathrm{CO}$ : Lanzhou vs. other cities in China.

As mentioned above, we construct the synthetic Lanzhou as the convex combination of cities in the control group, which most closely resembled Lanzhou in terms of the pre-reopening value of each predictor. The results are shown in Table 1, which compares the pre-reopening characteristics of the actual Lanzhou with those of the synthetic Lanzhou, as well as with the population-weighted average of the 14 cities in the control group.

We see that the average from cities that were not reactivated prior to February 21 does not provide a suitable control group for Lanzhou. Especially before reopening, the concentrations of all four air pollutants and other predictors were substantially different in the average of the 14 control cities from those in Lanzhou. In contrast, the synthetic Lanzhou accurately reproduces the concentration levels of $\mathrm{NO}_{2}, \mathrm{SO}_{2}, \mathrm{O}_{3}$, and $\mathrm{CO}$ and the values of their predictor variables in Lanzhou before reopening the economy. 
Table 1. Predictor means for $\mathrm{NO}_{2}, \mathrm{SO}_{2}, \mathrm{O}_{3}$, and $\mathrm{CO}$

\begin{tabular}{|c|c|c|c|}
\hline Variables & Real Lanzhou & Synthetic Lanzhou & Average of 14 control cities \\
\hline \multicolumn{4}{|l|}{ Panel A: $\mathrm{NO}_{2}\left(\mu \mathrm{g} / \mathrm{m}^{3}\right)$} \\
\hline LnGRPper (2019 CNY) & 11.20 & 11.44 & 11.48 \\
\hline Indushare (\%) & 98.43 & 97.15 & 96.47 \\
\hline $\mathrm{NO}_{2}$ (30Jan) & 62.00 & 33.26 & 26.36 \\
\hline $\mathrm{NO}_{2}(04 \mathrm{Feb})$ & 55.00 & 38.36 & 22.79 \\
\hline $\mathrm{NO}_{2}(10 \mathrm{Feb})$ & 66.00 & 46.86 & 29.79 \\
\hline $\mathrm{NO}_{2}(12 \mathrm{Feb})$ & 62.00 & 49.11 & 30.21 \\
\hline $\mathrm{NO}_{2}(17 \mathrm{Feb})$ & 56.00 & 30.98 & 17.43 \\
\hline $\mathrm{NO}_{2}(19 \mathrm{Feb})$ & 58.00 & 32.34 & 30.29 \\
\hline $\mathrm{NO}_{2}(20 \mathrm{Feb})$ & 16.00 & 19.28 & 28.21 \\
\hline \multicolumn{4}{|l|}{ Panel B: $\mathrm{SO}_{2}\left(\mu \mathrm{g} / \mathrm{m}^{3}\right)$} \\
\hline LnGRPper (2019 CNY) & 11.20 & 11.26 & 11.48 \\
\hline Indushare (\%) & 98.43 & 95.34 & 96.47 \\
\hline $\mathrm{SO}_{2}(31 \mathrm{Jan})$ & 28.00 & 24.54 & 14.14 \\
\hline $\mathrm{SO}_{2}(04 \mathrm{Feb})$ & 29.00 & 26.06 & 10.79 \\
\hline $\mathrm{SO}_{2}(06 \mathrm{Feb})$ & 26.00 & 33.62 & 10.29 \\
\hline $\mathrm{SO}_{2}(10 \mathrm{Feb})$ & 28.00 & 26.61 & 12.79 \\
\hline $\mathrm{SO}_{2}(14 \mathrm{Feb})$ & 8.00 & 12.65 & 7.00 \\
\hline $\mathrm{SO}_{2}(17 \mathrm{Feb})$ & 26.00 & 19.27 & 9.14 \\
\hline $\mathrm{SO}_{2}(2 \mathrm{OFeb})$ & 9.00 & 13.98 & 9.57 \\
\hline \multicolumn{4}{|l|}{ Panel C: $\mathrm{O}_{3}\left(\mu \mathrm{g} / \mathrm{m}^{3}\right)$} \\
\hline LnGRPper (2019 CNY) & 11.20 & 11.41 & 11.48 \\
\hline Indushare (\%) & 98.43 & 97.11 & 96.47 \\
\hline $\mathrm{O}_{3}(31 \mathrm{Jan})$ & 118.00 & 106.16 & 98.07 \\
\hline $\mathrm{O}_{3}(02 \mathrm{Feb})$ & 86.00 & 95.87 & 77.64 \\
\hline $\mathrm{O}_{3}(04 \mathrm{Feb})$ & 110.00 & 113.91 & 86.36 \\
\hline $\mathrm{O}_{3}(07 \mathrm{Feb})$ & 107.00 & 88.68 & 61.93 \\
\hline $\mathrm{O}_{3}(11 \mathrm{Feb})$ & 130.00 & 112.60 & 86.57 \\
\hline $\mathrm{O}_{3}(16 \mathrm{Feb})$ & 110.00 & 86.89 & 82.29 \\
\hline $\mathrm{O}_{3}(2 \mathrm{OFeb})$ & 80.00 & 89.99 & 79.93 \\
\hline \multicolumn{4}{|l|}{ Panel D: CO $\left(\mathrm{mg} / \mathrm{m}^{3}\right)$} \\
\hline LnGRPper (2019 CNY) & 11.20 & 11.34 & 11.48 \\
\hline Indushare (\%) & 98.43 & 96.43 & 96.47 \\
\hline CO (30Jan) & 2.00 & 1.27 & 1.07 \\
\hline $\mathrm{CO}(03 \mathrm{Feb})$ & 2.00 & 1.00 & 0.93 \\
\hline $\mathrm{CO}(06 \mathrm{Feb})$ & 2.00 & 1.25 & 1.07 \\
\hline $\mathrm{CO}(09 \mathrm{Feb})$ & 2.00 & 1.53 & 1.14 \\
\hline $\mathrm{CO}(12 \mathrm{Feb})$ & 2.00 & 1.27 & 1.21 \\
\hline $\mathrm{CO}(14 \mathrm{Feb})$ & 0.00 & 0.79 & 0.93 \\
\hline $\mathrm{CO}(20 \mathrm{Feb})$ & 0.00 & 1.27 & 1.07 \\
\hline
\end{tabular}

Note: $\mathrm{NO}_{2}$ (30Jan) means that the variable $\mathrm{NO}_{2}$ takes the value of January 30, and the rest may be deduced by analogy.

Table 2. City weights in the synthetic Lanzhou.

\begin{tabular}{llll}
\hline City & Weight & City & Weight \\
\hline $\begin{array}{l}\text { Panel A: } \mathrm{NO}_{2} \\
\text { Tianjin }\end{array}$ & 0.264 & Yinchuan & 0.736 \\
$\begin{array}{l}\text { Panel B: } \mathrm{SO}_{2} \\
\text { Harbin }\end{array}$ & 0.132 & Shijiazhuang & 0.143 \\
$\begin{array}{l}\text { Yinchuan } \\
\text { Panel C: } \mathrm{O}_{3}\end{array}$ & 0.725 & & \\
Xi'an & 0.077 & Zhengzhou & 0.249 \\
Yinchuan & 0.675 & & \\
Panel D: $\mathrm{CO}$ & & & \\
Tianjin & 0.264 & Shijiazhuang & 0.270 \\
Xi'an & 0.215 & Yinchuan & 0.252 \\
\hline
\end{tabular}

Note: The remaining cities not listed in Panel A, Panel B, Panel C, and Panel $\mathrm{D}$ are assigned 0 weights.
Table 2 displays the weights of each control city in the synthetic Lanzhou. The weights reported by Panel A in Table 2 indicate that the pre-reopening trend in $\mathrm{NO}_{2}$ concentrations in Lanzhou is best imitated by a combination of Tianjin and Yinchuan. Panel B shows that the $\mathrm{SO}_{2}$ trend in Lanzhou before reopening is best reproduced through a combination of Harbin, Shijiazhuang, and Yinchuan. According to Panel C, the pre-reopening $O_{3}$ trend in Lanzhou is best captured by a combination of Xi'an, Zhengzhou, and Yinchuan. Panel D suggests that a combination of Tianjin, Shijiazhuang, Xi'an, and Yinchuan can best reproduce the $C O$ trend in Lanzhou before reopening.

Figure 2 plots the daily trends in $\mathrm{NO}_{2}, \mathrm{SO}_{2}, \mathrm{O}_{3}$, and $\mathrm{CO}$ concentration levels in Lanzhou (red line) and synthetic Lanzhou (gray dashed line). Notice that, in contrast to the trends in other cities in China (as shown in Figure 1), the concentration of each air pollutant in the synthetic Lanzhou 
very closely tracks the trajectory of this variable in Lanzhou for the entire pre-reopening period. Combined with the high degree of balance on all predictors (Table 1), this suggests that the synthetic Lanzhou provides a reasonable approximation of
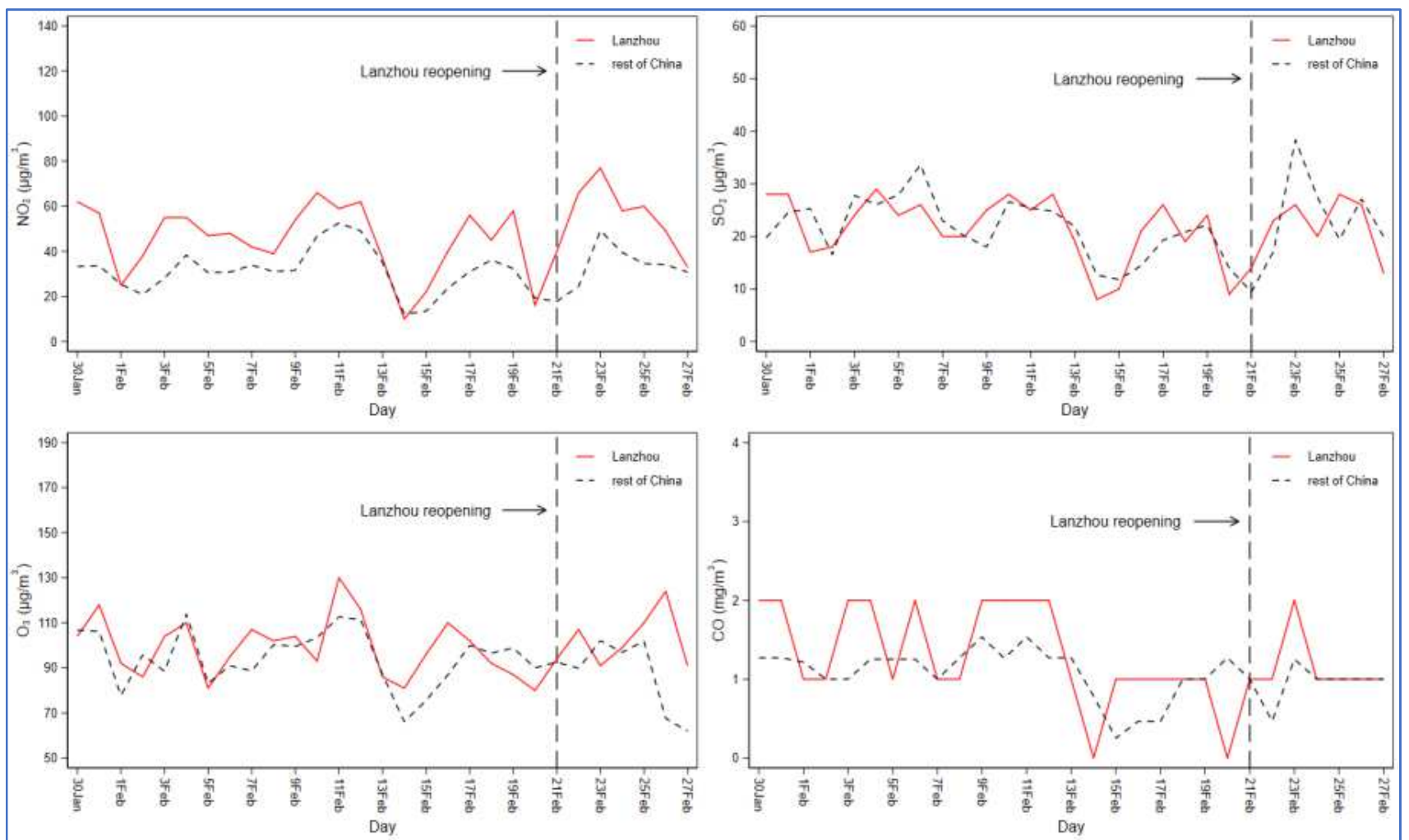

Figure 2. Trends in concentrations of $\mathrm{NO}_{2}, \mathrm{SO}_{2}, \mathrm{O}_{3}$, and $\mathrm{CO}$ : Lanzhou vs. synthetic Lanzhou.

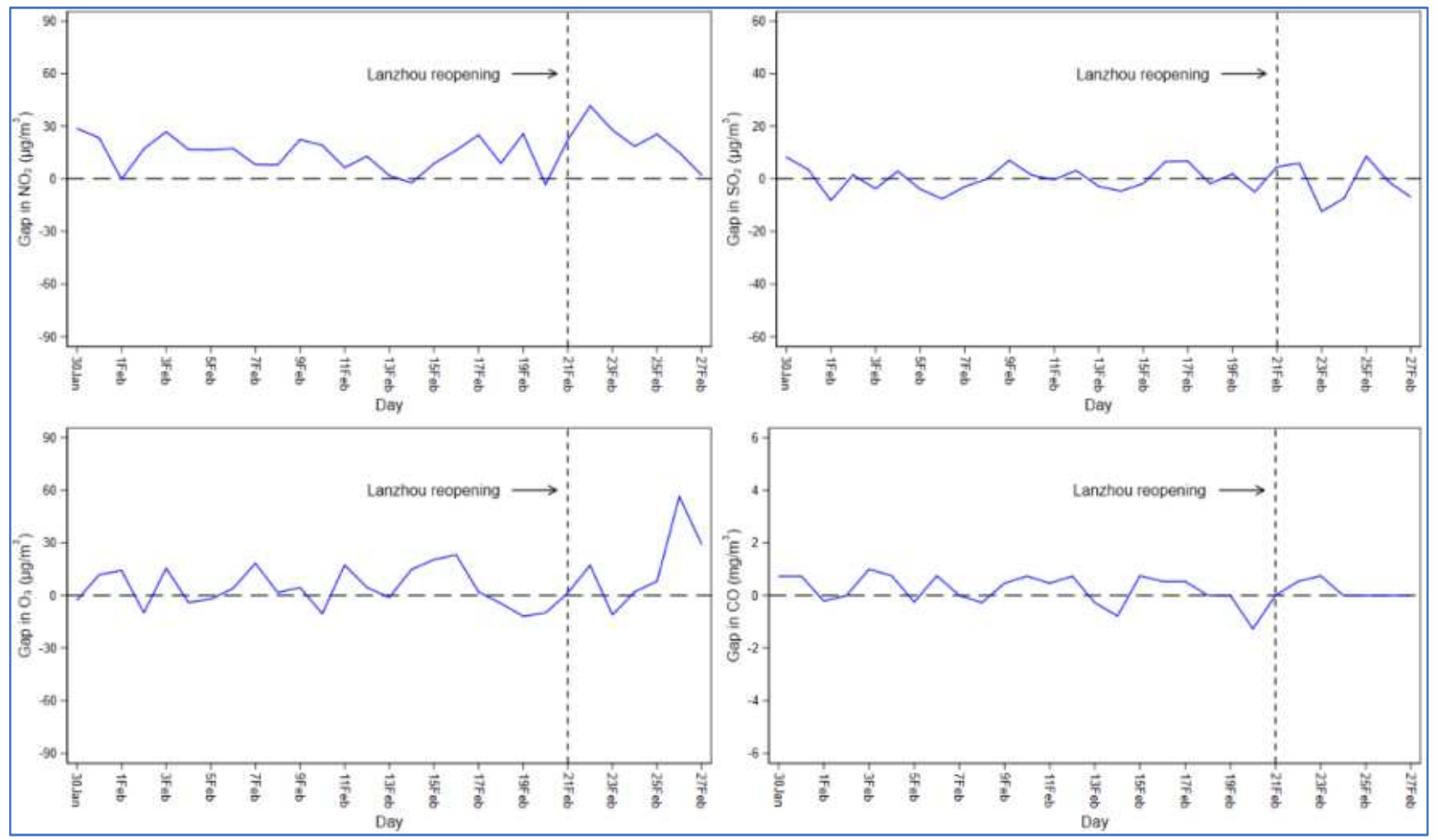

Figure 3. Gaps between Lanzhou and Synthetic Lanzhou in concentrations of $\mathrm{NO}_{2}, \mathrm{SO}_{2}, \mathrm{O}_{3}$, and $\mathrm{CO}$. 
Our estimate of the impact of reopening the economy on concentrations of four air pollutants in Lanzhou is the difference between the concentrations of $\mathrm{NO}_{2}, \mathrm{SO}_{2}, \mathrm{O}_{3}$, and $\mathrm{CO}$ in Lanzhou and in their synthetic versions respectively after reopening. Figure 3 plots the daily estimates (blue line) of the impact of reactivation. As shown in the figure, the trajectory of synthetic Lanzhou simulating the concentration of each air pollutant in real Lanzhou closely matched that of real Lanzhou before reopening.

Figure 2 shows that both trends for $\mathrm{NO}_{2}$ concentrations between January 30 and February 20 were around $40 \mu \mathrm{g} / \mathrm{m}^{3}$, which is the WHO safe limit. After January 21, 2020, as shown in Figure 3, a large and significant gap opens up between $\mathrm{NO}_{2}$ emissions in Lanzhou and synthetic Lanzhou with a peak difference of around $30 \mu \mathrm{g} / \mathrm{m}^{3}$, equivalent to an increase of $75 \%$ of the level of $\mathrm{NO}_{2}$ concentrations immediately after reopening. The gap between the series closes over time but still exceeds $20 \mu \mathrm{g} / \mathrm{m}^{3}$ on the 5 th day after restart and $2 \mu \mathrm{g} / \mathrm{m}^{3}$ at the end of the 7-day period. The results show that reopening the economy led to a large increase in $\mathrm{NO}_{2}$ level in Lanzhou. Road traffic is the largest source of $\mathrm{NO}_{2}$ concentrations in Chinese cities [12]. As the economy recovers, a marked increase in activity in the transport sector is the main reason for the increase in $\mathrm{NO}_{2}$ level in Lanzhou.

Moving on to $\mathrm{SO}_{2}$, Figure 2 shows that the $\mathrm{SO}_{2}$ level in Lanzhou before reopening was generally maintained at the WHO safe limit of $20 \mu \mathrm{g} / \mathrm{m}^{3}$. As shown in Figure 3, the SO2 level in Lanzhou after reopening was $10 \mu \mathrm{g} / \mathrm{m}^{3}$ higher than that when Lanzhou was not restarted, but decreased by 10 $\mu \mathrm{g} / \mathrm{m}^{3}$ immediately on the next day and increased again by approximately $10 \mu \mathrm{g} / \mathrm{m}^{3}$ on the 5 th day after reopening. $\mathrm{SO}_{2}$ is often produced by the combustion of fossil fuels in electricity generation and heating furnaces [14]. With the reactivation of the economy, industrial demand is gradually increasing while the demand for dirtier sources of residential electricity and heating, especially high-sulfur coal, by workers who originally stayed at home, is decreasing. The significant fluctuations in $\mathrm{SO}_{2}$ concentrations reflect the dynamic balance between residential demand for electricity and heating and industrial demand in the region.

We now consider $\mathrm{O}_{3}$. Figure 2 shows that the $\mathrm{O}_{3}$ level in Lanzhou before reopening was generally maintained at the WHO safe limit of $100 \mu \mathrm{g} / \mathrm{m}^{3}$. After reopening (as shown in Figure 3), the $\mathrm{O}_{3}$ level in Lanzhou increased by $15 \mu \mathrm{g} / \mathrm{m}^{3}$ compared with that before reopening. Notably, the $\mathrm{O}_{3}$ increase peaked at $60 \mu \mathrm{g} / \mathrm{m}^{3}$ on the 6th day after restarting, which corresponds to a $60 \%$ increase of the $\mathrm{O}_{3}$ concentration level. $\mathrm{O}_{3}$ is not emitted directly but is produced by the combination of nitrogen oxides $\left(\mathrm{NO}_{x}\right)$ and volatile organic compounds $\left(V O C_{s}\right)$ under high temperature and sunlight [14]. This is consistent with the delayed appearance of the peak.

Finally, as shown in Figure 2, the CO level in Lanzhou before reopening was around 0 to $2 \mathrm{mg} / \mathrm{m}^{3}$. Figure 3 shows that the $\mathrm{CO}$ level in Lanzhou on the second day after reopening was $1 \mathrm{mg} / \mathrm{m}^{3}$ higher than that when Lanzhou was not restarted. However, the increase in $\mathrm{CO}$ disappears 4 days after the restart and returns to the same trend followed by the other 14 cities. $\mathrm{CO}$ is released during combustion. Vehicles and machinery that burn fossil fuels emit carbon monoxide, as do home heating and cooking. With the lifting of the lockdown, a discernible increase in travel and industrial activity has increased $\mathrm{CO}$ concentrations. But less demand for residential heating and cooking sources will also offset the increase in industrial demand.

To assess the robustness of our results, we included additional predictors of air pollution levels among the variables used to construct the synthetic control. Regardless of which and how many predictor variables we added, our results remained virtually unaffected. The predictor variables used for robustness checks included daily maximum temperature, daily minimum temperature, population density, green space coverage in built-up areas, and investment in environmental governance to capture the climate, demographic, economic, and social structure of each city.

\section{Placebo Tests}

To validate the significance of our estimates, we need to answer the question of whether our results are entirely caused by chance. Following Abadie and Gardeazabal [19], Bertrand et al. [23], and Abadie et al. [20, 24], we perform a series of placebo tests. We start with an in-time placebo test and then estimate an in-place placebo test. The placebo test results convince us that our findings are not by chance.

\subsection{In-Time Placebo Test}

For the in-time placebo test, we assume that the Lanzhou reopening occurred on the same date but one year earlier, in 2019. Figure 4 displays the results of in-time placebo tests for $\mathrm{NO}_{2}, \mathrm{SO}_{2}, \mathrm{O}_{3}$, and $\mathrm{CO}$. We use the same setting and run the same code for the placebo test except for the reopening date. In Figure 4 we focus on the data period between January 30, 2019, to February 27, 2019, and then set the fake restart to be February 21, 2019. For the four in-time placebo tests we did not observe any significant increase in the four air pollutant concentration levels for this fake restart date.

\subsection{In-place Placebo Test}

We use the in-place placebo test to verify the possibility that we would obtain results of this magnitude if we had randomly selected a city for the study instead of Lanzhou. We iteratively apply the synthetic control method used to estimate the effect of reopening the economy in Lanzhou to every other city in the control group. In each iteration, we reassign the reopening intervention to one of the 14 control cities in our data and shift Lanzhou to the control group. We then calculate the estimated effect associated with each placebo run. This iterative process provides us with a distribution of estimated gaps for the cities that have not been reopened. If the placebo studies show that the gap estimated for Lanzhou is unusually large compared to the gaps for the cities that did not reopen, then our analysis provides significant evidence of the impact of reopening the economy on local air pollution levels in Lanzhou. Otherwise, our analysis 
does not provide significant evidence of the impact of reactivation.
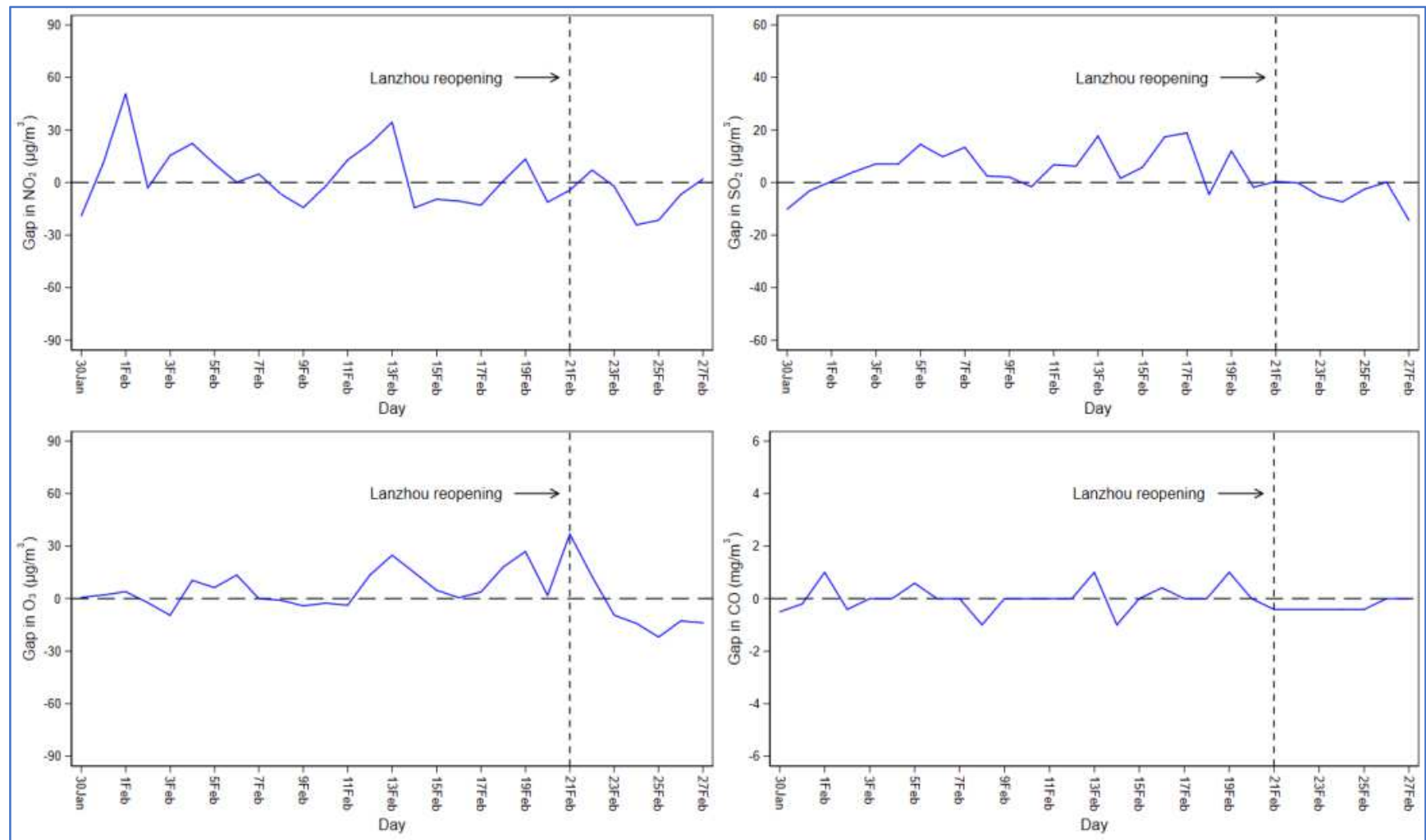

Figure 4. The in-time placebo test results of $\mathrm{NO}_{2}, \mathrm{SO}_{2}, \mathrm{O}_{3}$, and $\mathrm{CO}$.
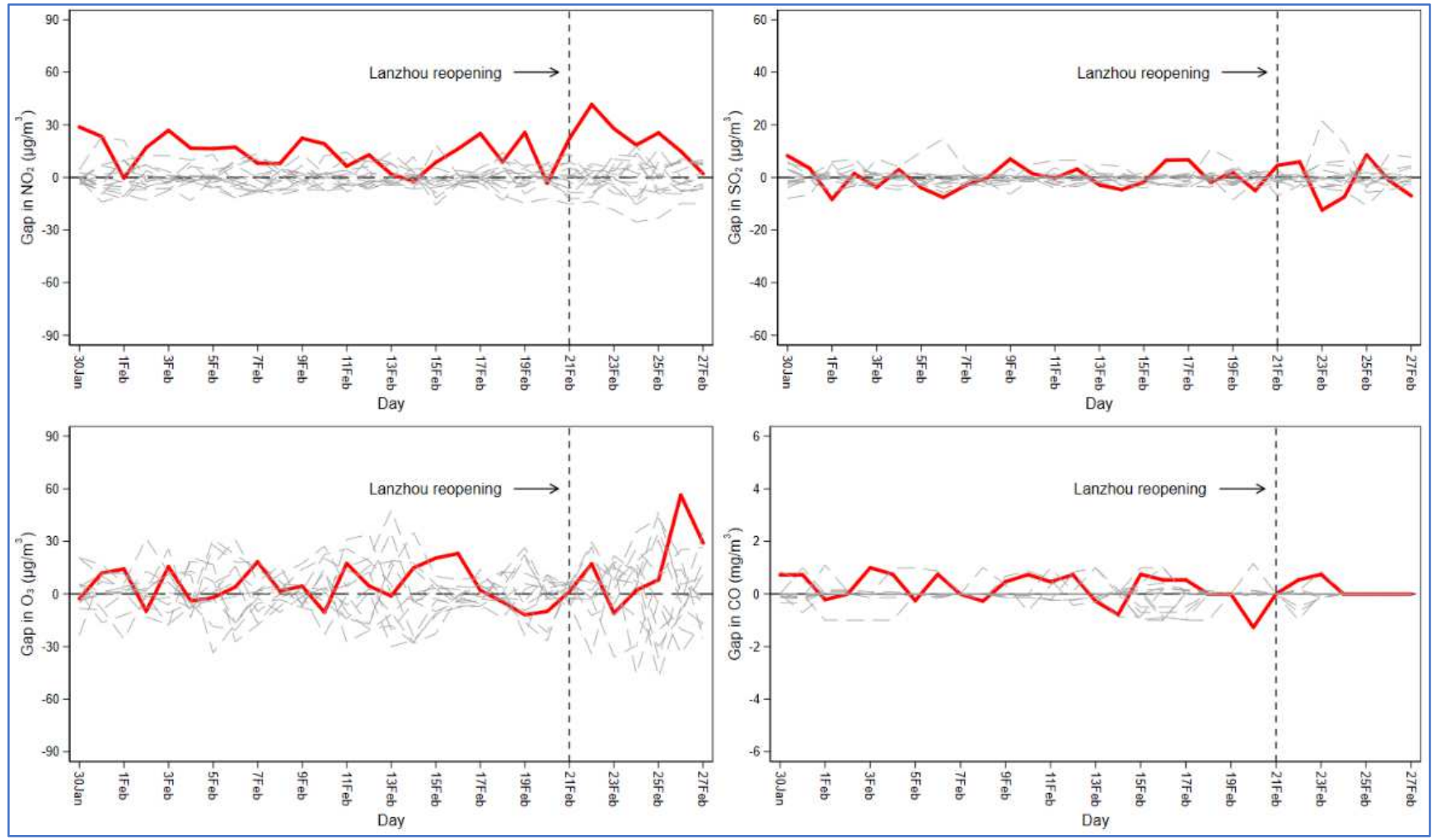

Figure 5. The results of in-place placebo tests on $\mathrm{NO}_{2}, \mathrm{SO}_{2}, \mathrm{O}_{3}$, and $\mathrm{CO}$.

Figure 5 depicts the results of in-place placebo tests for $\mathrm{NO}_{2}, \mathrm{SO}_{2}, \mathrm{O}_{3}$, and $\mathrm{CO}$. The gray dashed lines denote the difference in the air pollutant concentrations between each city in the control group and its respective synthetic version. The superimposed red line represents the gap estimated for Lanzhou. If the synthetic Lanzhou had failed to fit the air 
pollution levels for the real Lanzhou before reopening the economy, we would have argued that much of the post-reopening gap between the real and the synthetic Lanzhou was also artificially created by lack of matching, rather than by the effect of reopening. Therefore, in Figure 5 we focus only on cities that could have fit almost as well as Lanzhou during the pre-reopening period, that is, those cities that had a pre-reopening mean squared prediction error (MSPE) of less than twice the MSPE of Lanzhou. To do so we exclude Harbin for $\mathrm{SO}_{2}$, Chongqing and Harbin for $\mathrm{O}_{3}$, while for $\mathrm{NO}_{2}$ and $\mathrm{CO}$ we do not discard any cities.

As shown in Figure 5, almost all lines are tightly intertwined with the zero-gap line before reopening. This indicates that the synthetic control method provides an excellent fit for the concentrations of each air pollutant in Lanzhou before reopening. Specifically, the estimated gap in $\mathrm{NO}_{2}$ after reopening the economy in real Lanzhou is the largest relative to the distribution of gaps across cities in the control group, none of which showed a similar increase (over $30 \mathrm{\mu g} / \mathrm{m}^{3}$ ). Thus, reopening the economy significantly increased $\mathrm{NO}_{2}$ concentrations in Lanzhou. Next, after reopening, the $\mathrm{SO}_{2}$ trajectory in Lanzhou stands out among the other 13 control cities and fluctuates rapidly. In specific, $\mathrm{SO}_{2}$ concentrations in Lanzhou increased significantly after the reopening, then decreased significantly on the 3rd day and increased significantly again on the 5 th day. Moreover, while $\mathrm{O}_{3}$ concentrations in Lanzhou increased immediately after reopening, we only found a significant increase in $\mathrm{O}_{3}$ concentrations 6 days after reopening which is where the red line in the lower left figure shows the largest increase compared to the remaining grey dashed lines. Finally, the $C O$ gap estimated for Lanzhou is most unusual relative to the gaps for the other 14 cities within 4 days of reopening, indicating that reactivation made a significant contribution to the increase in $\mathrm{CO}$ concentrations in Lanzhou.

One final way to evaluate the Lanzhou gap relative to the gaps obtained from the in-place placebo runs is to look at the distribution of the ratios of post/pre-reopening MSPE. The main advantage of looking at ratios is that it avoids artificially choosing a cut-off point to exclude ill-fitting placebo runs. Besides, it helps to remove the impact of weather noise on local pollution concentration observations. Figure 6 displays the distribution of the post/pre-reopening ratios of the MSPE for Lanzhou and all 14 control cities for $\mathrm{NO}_{2}, \mathrm{SO}_{2}, \mathrm{O}_{3}$, and $\mathrm{CO}$. The ratio on $\mathrm{O}_{3}$ for Lanzhou stands out clearly in the figure. No other control city achieves such a large ratio. Therefore, the probability of obtaining a post/pre-reopening MSPE ratio for $\mathrm{O}_{3}$ as large as Lanzhou's under a random permutation of the intervention in our data is $0.067(1 / 15)$. Similarly, if we were to randomly assign the intervention in the data, the probability of obtaining post/pre-reopening MSPE ratios on $\mathrm{NO}_{2}, \mathrm{SO}_{2}$, and $C O$ as large as Lanzhou's is $0.100,0.091$, and 0.083 in turn. These results indicate that, relative to the control, the reopening of Lanzhou led to significant increases in $\mathrm{NO}_{2}, \mathrm{SO}_{2}, \mathrm{O}_{3}$, and $\mathrm{CO}$ concentrations.
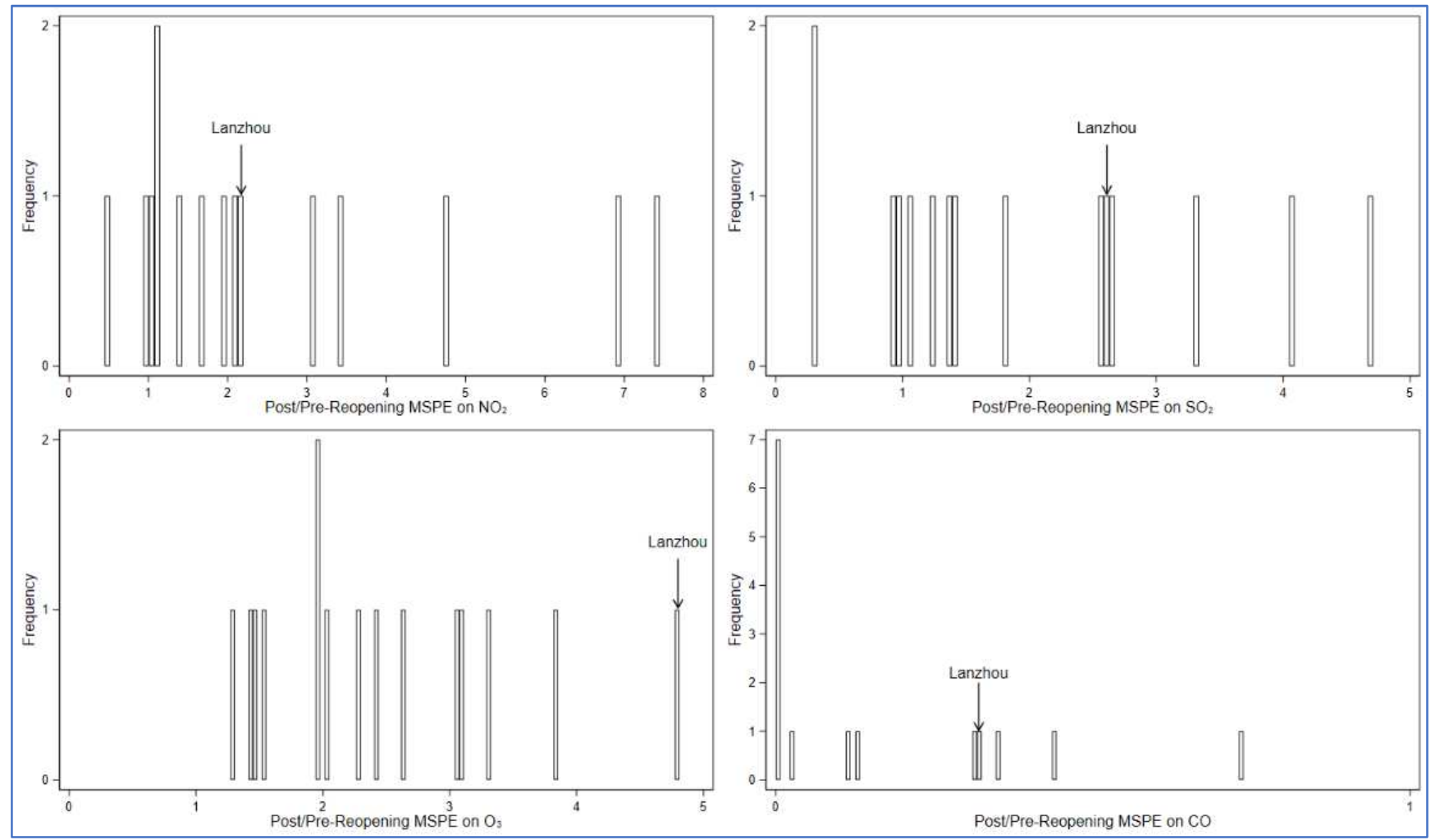

Figure 6. Ratios of post/pre-reopening MSPE for $\mathrm{NO}_{2}, \mathrm{SO}_{2}, \mathrm{O}_{3}$, and $\mathrm{CO}$.

\section{Conclusion}

The COVID-19 pandemic is shutting down countries around the world, causing a significant improvement in air quality in large cities as countries impose stricter quarantines and travel restrictions. However, the decline in air pollution 
caused by the virus outbreak may only be temporary. As regions open up again, industrial activity and human movement will augment the ambient pollutants, rapidly offsetting air improvements. It is therefore crucial and urgent to quantify the causal impact of reopening the economy during COVID-19 on local air quality. Based on the city-level daily air quality data in China, this study is the first to provide causal interpretations for the impact of reopening the economy of Lanzhou on local concentrations of four air pollutants using the synthetic control method. We find that concentrations of $\mathrm{NO}_{2}$, a pollutant strongly associated with traffic and fossil fuels, increased significantly by as much as $30 \mu \mathrm{g} / \mathrm{m}^{3}$ after reopening (a $75 \%$ increase from the lockdown level) although this increase declined to $2 \mu \mathrm{g} / \mathrm{m}^{3}$ by the end of our 7-day window of analysis. Concentrations of $O_{3}$ also increased significantly by $60 \mu \mathrm{g} / \mathrm{m}^{3}$ (a $60 \%$ increase) although this increase did not peak until 6 days after the restart. Note that the concentrations of $\mathrm{NO}_{2}$ and $\mathrm{O}_{3}$ after the lockdown were very close to their WHO health limits, so these increases brought these concentrations to exceed safe limits. Further, the reopening caused significant fluctuations in $\mathrm{SO}_{2}$ and $\mathrm{CO}$ concentrations, reflecting the dynamic balance between the demand for residential electricity and heating and industrial demand in the region.

Taken together, we cannot count on COVID-19 to improve air quality. But at the very least, the unplanned impact of this pandemic on air provides a glimpse of how countries and companies are prepared to deal with this slow moving but destructive air pollution crisis. While the threat of COVID-19 is serious, air pollution has an even more catastrophic impact on our health and life expectancy [25]. Therefore, if we want billions of people around the world to live longer and healthier lives, we must raise air quality to the level of a public health emergency, rely on economic stimulus packages that consider air quality, and take individual and collective action to protect it.

In our case, daily air pollution concentration levels in Lanzhou are highly volatile, reflecting the fact that pollutant concentrations are jointly influenced by emission levels and meteorological conditions. As a result, it is challenging to assess the impact of a policy intervention on pollutant concentrations [12, 26-28]. Therefore, removing the confounding effects of local weather conditions on pollution concentrations will be a constructive subject for future research. Furthermore, this paper shows that reopening the economy significantly increases $\mathrm{NO}_{2}, \mathrm{SO}_{2}, \mathrm{O}_{3}$, and $\mathrm{CO}$ concentrations in the short term (one-week period). Nevertheless, due to the limited time window of our sample data, we cannot definitively determine the long-term impact of reopening the economy on air pollution levels. In the long run, a healthy population (and environment) is essential for a healthy economy. More future research is needed to determine what is the best way to balance the trade-offs between what is good for the economy and what is good for public health.

\section{Declarations}

\section{Availability of Data and Material}

Not applicable.

\section{Conflicts of Interest}

The author declares no conflicts of interest regarding the publication of this paper.

\section{Funding}

No funding received.

\section{Acknowledgements}

I am most grateful to Professor John Mullahy for his helpful suggestions. I thank the editor and anonymous referees for their valuable comments. I also thank Ruize Liu for collecting data on air quality used in this study. All remaining errors are my own.

\section{References}

[1] Chen, S., Yang, J., Yang, W., Wang, C., \& Bärnighausen, T. (2020). COVID-19 control in China during mass population movements at New Year. The Lancet, 395 (10226), 764-766.

[2] Qiu, Y., Chen, X., \& Shi, W. (2020). Impacts of social and economic factors on the transmission of coronavirus disease 2019 (COVID-19) in China. Journal of Population Economics, 1.

[3] Chan, J. F. W., Yuan, S., Kok, K. H., To, K. K. W., Chu, H., Yang, J.,... \& Tsoi, H. W. (2020). A familial cluster of pneumonia associated with the 2019 novel coronavirus indicating person-to-person transmission: a study of a family cluster. The Lancet, 395 (10223), 514-523.

[4] Bajardi, P., Poletto, C., Ramasco, J. J., Tizzoni, M., Colizza, V., \& Vespignani, A. (2011). Human mobility networks, travel restrictions, and the global spread of $2009 \mathrm{H} 1 \mathrm{~N} 1$ pandemic. PloS one, 6 (1), e16591.

[5] Wang, Q., \& Taylor, J. E. (2016). Patterns and limitations of urban human mobility resilience under the influence of multiple types of natural disaster. PLoS one, 11 (1), e0147299.

[6] Charu, V., Zeger, S., Gog, J., Bjørnstad, O. N., Kissler, S., Simonsen, L.,... \& Viboud, C. (2017). Human mobility and the spatial transmission of influenza in the United States. PLoS computational biology, 13 (2), e1005382.

[7] Fang, H., Wang, L., \& Yang, Y. (2020). Human mobility restrictions and the spread of the novel coronavirus (2019-ncov) in china. Journal of Public Economics, 191, 104272.

[8] New York Times (2020) Watch the footprint of coronavirus spread across countries, March 17th. https://www.nytimes.com/interactive/2020/climate/coronaviru s-pollution.html. Accessed 27 Aug 2020.

[9] Guardian (2020) Coronavirus pandemic leading to huge drop in air pollution, March 23rd. https://www.theguardian.com/environment/2020/mar/23/coro navirus-pandemic-leading-to-huge-drop-in-air-pollution. Accessed 27 Aug 2020.

[10] Independent (2020) Coronavirus: air pollution drops in UK cities as life comes to a halt with nationwide lockdown, March 24th. $\mathrm{https}: / / \mathrm{www}$.independent.co.uk/environment/coronavirus-air-poll ution-uk-lockdown-china-italy-covid-19-a9421291.html. Accessed 27 Aug 2020. 
[11] Space (2020) Italy's coronavirus response dramatically reduces air pollution emissions, satellites show, March 13th. https://www.space.com/italy-coronavirus-outbreak-response-r educes-emissions-satellite-images.html. Accessed 27 Aug 2020.

[12] Cole, M. A., Elliott, R. J., \& Liu, B. (2020). The impact of the Wuhan Covid-19 lockdown on air pollution and health: a machine learning and augmented synthetic control approach. Environmental and Resource Economics, 1-28.

[13] He, G., Pan, Y., \& Tanaka, T. (2020). The short-term impacts of COVID-19 lockdown on urban air pollution in China. Nature Sustainability, 1-7.

[14] Almond, D., Du, X., \& Zhang, S. (2020). Did COVID-19 Improve Air Quality Near Hubei? (No. w27086). National Bureau of Economic Research.

[15] Cicala, S., Holland, S. P., Mansur, E. T., Muller, N. Z., \& Yates, A. J. (2020). Expected Health Effects of Reduced Air Pollution from COVID-19 Social Distancing (No. w27135). National Bureau of Economic Research.

[16] Brodeur, A., Cook, N., \& Wright, T. (2020). On the Effects of COVID-19 Safer-At-Home Policies on Social Distancing, Car Crashes and Pollution.

[17] Dang, H. A., \& Trinh, T. A. (2020). Does the COVID-19 pandemic improve global air quality? New cross- national evidence on its unintended consequences.

[18] Tian, H., Liu, Y., Li, Y., Wu, C. H., Chen, B., Kraemer, M. U.,... \& Wang, B. (2020). An investigation of transmission control measures during the first 50 days of the COVID-19 epidemic in China. Science, 368 (6491), 638-642.

[19] Abadie, A., \& Gardeazabal, J. (2003). The economic costs of conflict: A case study of the Basque Country. American economic review, 93 (1), 113-132.
[20] Abadie, A., Diamond, A., \& Hainmueller, J. (2010). Synthetic control methods for comparative case studies: Estimating the effect of California's tobacco control program. Journal of the American statistical Association, 105 (490), 493-505.

[21] Abadie, A. (2019). Using synthetic controls: Feasibility, data requirements, and methodological aspects. Journal of Economic Literature.

[22] Athey, S., \& Imbens, G. W. (2017). The state of applied econometrics: Causality and policy evaluation. Journal of Economic Perspectives, 31 (2), 3-32.

[23] Bertrand, M., Duflo, E., \& Mullainathan, S. (2004). How much should we trust differences-in-differences estimates?. The Quarterly journal of economics, 119 (1), 249-275.

[24] Abadie, A., Diamond, A., \& Hainmueller, J. (2015). Comparative politics and the synthetic control method. American Journal of Political Science, 59 (2), 495-510.

[25] Fuentes, R., Galeotti, M., Lanza, A., \& Manzano, B. (2020). COVID-19 and Climate Change: A Tale of Two Global Problems. Available at SSRN 3604140.

[26] Anh, V., Duc, H., \& Azzi, M. (1997). Modeling anthropogenic trends in air quality data. Journal of the Air \& Waste Management Association, 47 (1), 66-71.

[27] Grange, S. K., Carslaw, D. C., Lewis, A., Boleti, E., \& Heuglin, C. (2018). Random forest meteorological normalisation models for Swiss PM10 trend analysis. Atmospheric Chemistry and Physics Discussions.

[28] Grange, S. K., \& Carslaw, D. C. (2019). Using meteorological normalisation to detect interventions in air quality time series. Science of The Total Environment, 653, 578-588. 